Systematic Review

\title{
Adverse Outcomes Associated with Prescription Opioids for Acute Low Back Pain: A Systematic Review and Meta-Analysis
}

Nitika Sanger, $\mathrm{HBSc}^{1}$, Meha Bhatt, MSc${ }^{2}$, Nikhita Singhal, BHsc ${ }^{3}$, Katherine Ramsden, MD4, Natasha Baptist-Mohseni, Bsc ${ }^{5}$, Balpreet Panesar, BSc ${ }^{6}$, Hamnah Shahid, BASc ${ }^{7}$, Alannah Hillmer, BSc ${ }^{5}$, Alessia D’Elia, BSc${ }^{1}$, Candice Luo, $\mathrm{BHSc}^{8}$, Victoria Rogers, $\mathrm{BSc}^{5}$, Abirami Arunan, $\mathrm{HBSc}^{9}$, Lola Baker-Beal, Bsc ${ }^{10}$, Sean Haber, BSc ${ }^{3}$, Jihane Henni, BSc ${ }^{11}$, Megan Puckering, BSc ${ }^{3}$, Sunny Sun, BSc ${ }^{3}$, Kim Ng, BSc ${ }^{3}$, Stephanie Sanger, MLIS ${ }^{12}$, Natalia Mouravaska, MD ${ }^{13}$, M. Constantine Samaan, MD ${ }^{14}$, Russell de Souza, ScD², Lehana Thabane, $\mathrm{PhD}^{2}$, and Zainab Samaan, $\mathrm{PhD}^{1,2}$

From: ${ }^{1}$ Department of Psychiatry and Behavioural Neurosciences, McMaster University, Hamilton, ON; ${ }^{2}$ Department of Health Research Methods, Evidence and Impact, McMaster University, Hamilton, ON; 3 Undergraduate MD Program, McMaster University, Hamilton, ON; ${ }^{4}$ Department of Medicine, McMaster University, Hamilton, Ontario, Canada; 5Department of Psychology, Neuroscience and Behaviour, McMaster University, Hamilton, ON; ' ${ }^{6}$ epartment of Biology, McMaster Úniversity, Hamilton, ON;

${ }^{7}$ Arts \& Sciences, McMaster University,

Hamilton, Ontario; ${ }^{8}$ Health Sciences, McMaster University, Hamilton, Ontario,

Canada; ${ }^{9}$ Faculty of Medicine, University

of Sydney, Camperdown, Australia; ${ }^{\circ} \mathrm{St}$. George's Medical School, St. George's Hospital, Cranmer Terrace, London, UK; ${ }^{11}$ College of Medicine, University of Saskatchewan, Saskatoon, SK; ${ }^{12} \mathrm{Health}$ Science Library, McMaster University, Hamilton, ON; ${ }^{13}$ Mood Disorders Research Unit, St. Joseph's Healthcare Hamilton, Hamilton, ON; ${ }^{14}$ Division of Pediatric Endocrinology, McMaster Children's
Hospital, Hamilton, ON

Address Correspondence: Zainab Samaan, PhD

Mood Disorders Program, St. Joseph's Healthcare Hamilton 100 West 5 th St. Hamilton, ON, L8N $3 \mathrm{~K}_{7}$ E-mail: samaanz@mcmaster.ca

Disclaimer: Dr. Samaan is supported by grants from CIHR Award \#156306, Bridge

CIHR Sponsor Award \#PJT-153429 and HAHSO Sponsor Award \#HAH-16-o4.

There was no external funding in the preparation of this manuscript. preparation of this manuscript.
Conflict of interest: Each author certifies that he or she, or a member of his or her immediate family, has no commercial association (i.e., consultancies, stock ownership, equity interest, patent/licensing arrangements, etc.) that might pose a conflict of interest in connection with the submitted manuscript.

Manuscript received: $07-24-2018$ Accepted for publication:

$09-17-2018$

Free full manuscript: www.painphysicianjournal.com
Background: Acute low back pain (ALBP) is a common clinical complaint that can last anywhere from 24 hours to 12 weeks. In recent years, there has been an opioid epidemic which is linked to the increased availability of prescription opioids. Though guidelines recommend that in the treatment of ALBP, opioids should be used when other treatments fail, we have seen an increase in opioid prescriptions for ALBP. With this crisis, it is important to examine if there are any adverse outcomes associated with prescribing opioids for ALBP.

Objective: We aim to review the published literature to examine the adverse outcomes associated with opioid use for ALBP.

Study Design: We performed a systematic review with meta-analysis in accordance with our published protocol and PRISMA guidelines.

Setting: The review was conducted at McMaster University.

Methods: Various electronic databases for articles published from inception to September 30,2017 , inclusive. Both randomized clinical trials and observational studies on the impact of opioid use in ALBP in the adult population were included. Eight pairs of independent reviewers performed screening, data extraction, and assessment of methodological quality. The identified articles were assessed for risk of bias using sensitivity analysis. Trials with comparative outcomes were reported in a meta-analysis using a fixed effects model.

Results: A total of 13,889 studies were initially screened for the review and a total of 4 studies were included in the full review, of which 2 studies were meta-analyzed. Our results showed that prescribing opioids for ALBP was significantly associated with longterm continued opioid use $(1.57,95 \% \mathrm{Cl}, 1.06-2.33)$. There was no significant association found between unemployment duration and prescribing opioids for $\operatorname{ALBP}(3.54,95 \% \mathrm{Cl}$, -7.57 to 14.66$)$

Limitations: Due to the limited number of studies that considered unemployment, only an unpooled analysis was conducted. Among the included studies there was both statistical and clinical heterogeneity due to differences in methodology, study design, risk of selection or performance bias. Most of the studies had an unclear or high risk of bias and poorly defined side effects.

Conclusions: Due to the lack of literature examining long-term adverse outcomes associated with prescribing opioids for ALBP, no definitive conclusions can be made. However, with the literature available, there does seem to be risk associated with prescribing opioids for ALBP so there is a great need to conduct further investigations examining these adverse outcomes for ALBP patients.

Key words: Acute low back pain, opioids, prescriptions, low back pain, long-term use, opioid use disorder

Pain Physician 2019: 22:119-138 
n general, low back pain causes discomfort and pain to a wide number of people each year $(1,2)$ and has become an extremely common clinical complaint (3). Acute low back pain (ALBP) is a major cause of disability and is described as pain in the inferior gluteal and costal margin (3-5). This pain typically lasts between 24 hours and 12 weeks (5). Even though a large proportion of ALBP patients recover within 14 days, recurrent pain is experienced by about $70 \%$ of ALBP patients within one year of onset $(6,7)$. Additionally, a previous study reported that $85 \%$ of all acute back pain is nonspecific and hence, it cannot be ascribed to a definite cause (8). However, research has shown that some of the main causes include trauma, malignancy or bone metastasis, infective cases like an abscess and osteomyelitis, and inflammatory conditions like HLA-B27 arthritis (9-11). ALBP remains a leading cause of disability as well as a major public health problem (12).

The use of non-opioid therapy is the main recommendation for the management of ALBP. The current framework given by the American College of Physicians, as well as the American Pain Society and the European guidelines for managing low back pain in primary care, recommend the use and application of non-opioid therapies like nonsteroidal anti-inflammatory drugs as the initial line of treatment for low back pain $(5,10,13)$. The guidelines further propose that opioids need to be used for ALBP only in severe cases, particularly when other forms of medications and treatments are deemed ineffective $(5,10)$. Opioid prescriptions for ALBP have greatly increased, though their effectiveness is yet to be supported by evidence (14). Moreover, research has indicated that work loss linked with back pain is more likely for people who have taken opioids compared to those who have not (15).

Deyo et al (16) found that over $2 \%$ of US adults reported regular prescription and use of opioids, and more than half of these have low back pain. The research suggests that many of the patients who use prescribed opioids have persistently high levels of low back pain. It has been suggested that despite uncertainties about their long-term safety and efficacy for ALBP, the use of prescription opioids for ALBP has risen rapidly in parallel with the opioid crisis (17).

In Canada, opioid misuse through physician prescription is rampant (18). The Canadian Center on Substance Abuse (CCSA) in 2013 devised a prevention strategy that involved education of the public, patients, and physicians (19). It also devised an evidence-based policy recommendation to avoid the harm of addiction and improve prescription practices. Despite the CCSA's efforts, the use of opioids is still high in some parts of Canada. In Ontario, mortality due to prescribed opioid use has increased (20). Opioid use disorder has also led to societal problems like criminality and increased disease infection rates $(18,21,22)$. A recent investigation by Bawor et al found that more than half of the women as well as a third of the men diagnosed with opioid use disorder were first introduced to opioids through a legitimate prescription (23). There remains a gap in the literature investigating the incidence of abuse, misuse, or dependence (opioid use disorder) after being prescribed opioids for ALBP (24).

Evidence for long-term misuse of opioids, as well as other adverse outcomes following prescription of opioids for ALBP, have not been examined systematically. This lack of research makes it difficult for clinicians to make informed treatment-related decisions, and for patients to make informed decisions regarding their own treatment. This review will make a critical and significant contribution to the practice of prescribing and use of opioids for ALBP management -a common debilitating condition experienced by many people.

\section{Objectives}

The objective of this review was to conduct a systematic review and meta-analysis of the literature investigating adverse outcomes associated with prescribing opioids for ALBP. Adverse outcomes of interest included prescription abuse, misuse, continued long-term use, development of opioid use disorder, unemployment, social adversity, marital discord, criminal activity, and mortality.

\section{Methods}

\section{Protocol and Registration}

This systematic review was conducted to investigate adverse outcomes associated with prescription opioid use for adult ALBP patients. The Preferred Reporting Items for Systematic Review and Meta-Analysis (PRISMA) guidelines were followed (25). The protocol for this systematic review has been published previously and registered with PROSPERO (registration number CRD42016033090) (26).

\section{Eligibility Criteria}

We included studies reporting on patients 18 years or older, gender, and ethnicity. Patients with a primary diagnosis of ALBP (as defined by reporting low back pain of $\leq 12$ weeks without a clear and specific attributable 
cause) (4) in any setting were included. Inclusion criteria for participation were those studies describing prescription opioids for ALBP and reporting on the duration of use, follow-up, incident misuse, social adversity, side effects, and mortality. Eligible study designs included randomized controlled trials (RCTs), observational studies (including cohort and cross-sectional designs), pilot or feasibility studies (powered), and other trial designs (e.g., cross-over and cluster RCTs).

\section{Information Sources and Search Strategy}

The following electronic databases were searched from inception to September 30, 2017 with no language limitations: PubMed, EMBASE, PsycINFO, CINAHL, and Web of Science. In addition, we searched trial databases of the National Institutes for Health Clinical Trials Registry, Cochrane Trials Registry, and the World Health Organization International Clinical Trials Registry Platform (WHO ICTRP). We also conducted a manual search of reference lists from identified studies, relevant articles, and systematic reviews; key journals; as well as grey literature. Search terms were related to ALBP, prescription opioids, and MeSH terms (Table 1, Appendix 1). Study authors were contacted when outcome data were insufficient for analysis.

\section{Study Selection}

Eight pairs of reviewers independently performed the initial and subsequent screenings and data extraction of the articles according to the set of inclusion and exclusion criteria. When there was disagreement, resolution was reached by either discussion to consensus, or by consultation with a third party if it remained unresolved.

\section{Data Collection and Data Items}

After identifying relevant studies, the following data were extracted from the full texts of the studies using piloted standardized forms: author, year of study, country, study design, patient demographics (number, age, and gender), intervention (type of prescription, dose and duration of treatment), comparators, and main outcome measures. In addition, we extracted data on statistical results obtained in each identified study. For the extraction form, please see Appendix 2.

\section{Risk of Bias of Individual Studies}

Two reviewers conducted independent assessments of the methodological quality of eligible studies; a modified version of the Newcastle-Ottawa Scale that
Table 1. Example of search strategy.

\begin{tabular}{|c|c|}
\hline \multirow{21}{*}{ MEDLINE $=669$} & 1 exp Acute Pain \\
\hline & 2 exp Low Back Pain \\
\hline & exp Analgesics, Opioid \\
\hline & 4 exp Morphine \\
\hline & 5 exp Codeine \\
\hline & 6 exp Fentanyl \\
\hline & 7 exp Tramadol \\
\hline & 8 exp Meptazinol \\
\hline & 9 exp Pentazocine \\
\hline & 10 exp Methadone \\
\hline & 11 exp Buprenorphine \\
\hline & 12 oxycodone.mp. \\
\hline & 13 dipipanone.mp. \\
\hline & 14 remifentanil.mp. \\
\hline & 15 papaveretum.mp. \\
\hline & 16 pethidine.mp. \\
\hline & 17 tapentadol.mp. \\
\hline & 181 or 2 \\
\hline & $\begin{array}{l}193 \text { or } 4 \text { or } 5 \text { or } 6 \text { or } 7 \text { or } 8 \text { or } 9 \text { or } 10 \text { or } 11 \text { or } \\
12 \text { or } 13 \text { or } 14 \text { or } 15 \text { or } 16 \text { or } 17\end{array}$ \\
\hline & $20 \quad 18$ and $19(728)$ \\
\hline & 21 limit 20 to humans (701) \\
\hline
\end{tabular}

has been modified for cross-sectional studies was used to assess the risk of bias for the observational studies (27). Eight items in the Newcastle-Ottawa scale were categorized into criteria based on study selection, comparability, and appropriateness of outcome measures. For randomized controlled studies, the Cochrane Risk of Bias tool was applied to eligible studies to assess all sources of bias (such as selection bias, attribution bias, reporting bias, etc.) (28). The quality and strength of evidence was assessed using the Grading of Recommendations Assessment, Development and Evaluation (GRADE) criteria and summarized in Table 2 (29).

\section{Statistical Analyses}

We have presented our findings both qualitatively and quantitatively. Where possible we have reported on population characteristics associated with experiencing adverse events as well as intervention characteristics such as prescription patterns, doses and types of opioids, duration of treatment, and whether any specific guidelines were followed.

We have presented pooled dichotomized data as odds ratios (OR) with $95 \%$ confidence intervals and pooled continuous data as mean differences (MD) or stan- 
Table 2. Summary of findings.

\begin{tabular}{|c|c|c|c|c|c|c|c|c|c|c|}
\hline \multicolumn{5}{|c|}{ Certainty Assessment } & \multicolumn{2}{|c|}{ No. of patients } & \multicolumn{2}{|l|}{$\overline{\text { Effect }}$} & \multirow[b]{2}{*}{ Certainty } & \multirow[b]{2}{*}{ Importance } \\
\hline $\begin{array}{l}\text { No. of } \\
\text { studies }\end{array}$ & $\begin{array}{l}\text { Study } \\
\text { Design }\end{array}$ & $\begin{array}{l}\text { Risk } \\
\text { of bias }\end{array}$ & $\begin{array}{l}\text { Inconsistency/ } \\
\text { Indirectness/ } \\
\text { Imprecision }\end{array}$ & $\begin{array}{l}\text { Other } \\
\text { considerations }\end{array}$ & $\begin{array}{l}\text { Early } \\
\text { Opioid } \\
\text { Use }\end{array}$ & $\begin{array}{l}\text { No } \\
\text { Opioid } \\
\text { Use }\end{array}$ & $\begin{array}{l}\text { Relative } \\
(95 \% \\
\text { CI) }\end{array}$ & $\begin{array}{l}\text { Absolute } \\
\text { (95\% CI) }\end{array}$ & & \\
\hline \multicolumn{11}{|c|}{ Unemployment } \\
\hline 2 & $\begin{array}{l}\text { observational } \\
\text { studies }\end{array}$ & $\begin{array}{l}\text { not } \\
\text { serious }\end{array}$ & $\begin{array}{l}\text { not serious / } \\
\text { not serious / } \\
\text { serious }^{\text {a }}\end{array}$ & $\begin{array}{l}\text { all plausible } \\
\text { residual } \\
\text { confounding } \\
\text { would } \\
\text { reduce the } \\
\text { demonstrated } \\
\text { effect }\end{array}$ & 786 & 9189 & - & $\begin{array}{l}\text { MD } 3.54 \\
\text { higher } \\
\text { ( } 7.57 \text { lower } \\
\text { to } 14.66 \\
\text { higher) }\end{array}$ & $\begin{array}{l}\oplus \oplus \bigcirc \bigcirc \\
\text { Low }\end{array}$ & Important \\
\hline \multicolumn{11}{|c|}{ Late Opioid Use } \\
\hline 2 & $\begin{array}{l}\text { observational } \\
\text { studies }\end{array}$ & $\begin{array}{l}\text { not } \\
\text { serious }\end{array}$ & $\begin{array}{l}\text { serious }^{\mathrm{b} /} \\
\text { not serious/ } \\
\text { not serious }\end{array}$ & $\begin{array}{l}\text { all plausible } \\
\text { residual } \\
\text { confounding } \\
\text { would } \\
\text { reduce the } \\
\text { demonstrated } \\
\text { effect }\end{array}$ & $\begin{array}{l}134 / 786 \\
(17.0 \%)\end{array}$ & $\begin{array}{l}\text { 932/9189 } \\
(10.1 \%)\end{array}$ & $\begin{array}{l}\text { RR } 1.57 \\
\text { (1.06 to } \\
2.33)\end{array}$ & $\begin{array}{l}58 \text { more } \\
\text { per } 1,000 \\
\text { (from } 6 \\
\text { more to } 135 \\
\text { more) }\end{array}$ & $\begin{array}{l}\oplus \oplus \bigcirc \bigcirc \\
\text { Low }\end{array}$ & Critical \\
\hline \multicolumn{11}{|c|}{ Side Effects } \\
\hline 2 & $\begin{array}{l}\text { randomised } \\
\text { trials }\end{array}$ & $\begin{array}{l}\text { not } \\
\text { serious }\end{array}$ & $\begin{array}{l}\text { serious }^{\mathrm{cl}} \\
\text { serious }^{\mathrm{d} /} \\
\text { serious }^{\mathrm{e}}\end{array}$ & none & \multicolumn{4}{|c|}{$\begin{array}{l}\text { One study reported that the group receiving opioids } \\
\text { as treatment experienced worse side effects than the } \\
\text { group receiving alternative drug whereas another } \\
\text { study reported both groups experiencing a similar } \\
\text { number of side effects. }\end{array}$} & $\begin{array}{l}\oplus \bigcirc \bigcirc \bigcirc \\
\text { Very Low }\end{array}$ & Important \\
\hline
\end{tabular}

CI: Confidence interval; MD: Mean difference; RR: Risk ratio

a. Imprecise as adjusted pooled estimates were not possible to conduct.

b. Inconsistent due to high heterogeneity and large variation across study characteristics, including population, sample size and method of measuring late opioid use.

c. High degree of variability in side effects reported.

d. Often looking at adverse events profile, not specifically exploring established opioid-related side effects.

e. Pooled estimate was not possible as there was large variation between studies as to what side-effects were measured and there was also variation in drugs that were being compared.

dardized mean differences (SMD) with 95\% confidence intervals. We have quantified data heterogeneity using the I-squared statistics greater than $40 \%$ since Cochrane has indicated that a value less than $40 \%$ may not be a representation of significant heterogeneity (30). To account for confounding, adjusted analyses from observational studies were used. Meta-analysis was conducted using RevMan 5.2 (The Nordic Cochrane Centre for The Cochrane Collaboration, Copenhagen, Denmark). We were unable to assess publication bias, as studies have reported that this is not possible for fewer than 10 studies (31). We followed the PRISMA reporting guidelines (Fig. 1).

\section{Types of Interventions}

\section{Experimental}

The experimental intervention included prescriptions of any type of opioid for the treatment of ALBP.
The types of opioids included morphine, diamorphine, fentanyl, alfentanil, remifentanil, methadone, oxycodone, pethidine, tapentadol, tramadol, codeine, dihydrocodeine, and meptazinol.

\section{Comparators}

The accepted comparators included placebo/not prescribed any opioids, any non-opioid analgesics, and any complementary therapies.

\section{Outcome Measures}

\section{Continued Opioid Use}

We have defined continued opioid use as ongoing opioid use beyond the needed time to treat for ALBP. ALBP is a pain condition that does not last more than 12 weeks by definition. Continued opioid use may be measured in a variety of ways, such as us- 


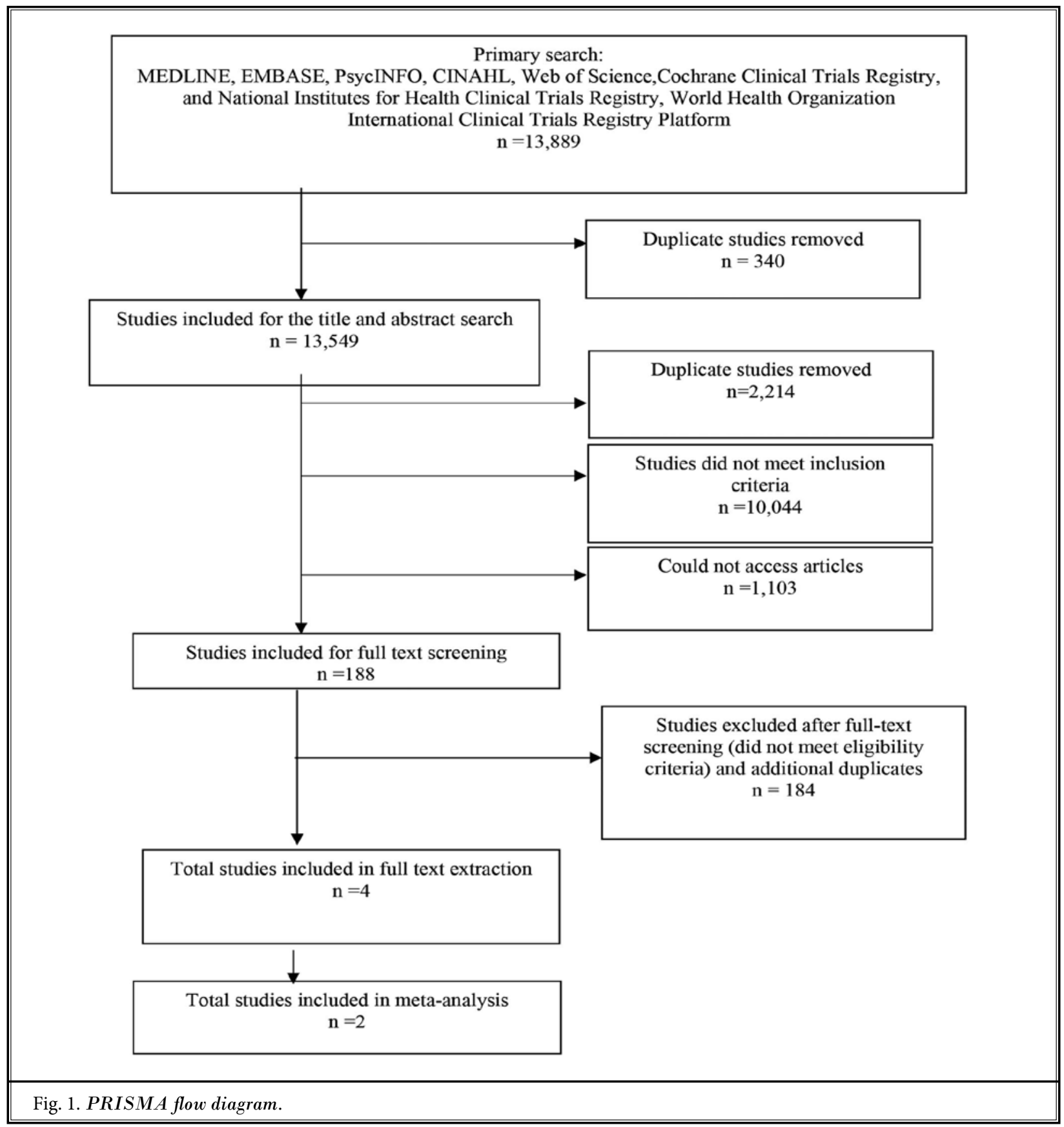

ing a prescription monitoring system to determine if additional prescriptions were prescribed beyond the need to treat ALBP or through urine screens testing for opioids. A full list of outcome measures can be found in Table 3.

\section{Unemployment}

Unemployment is defined as the total time an individual has not worked since being diagnosed with ALBP. This can also be measured in varied ways including disability claims, self-report, and government records. A full list of outcomes for unemployment can be found in Table 3 . 


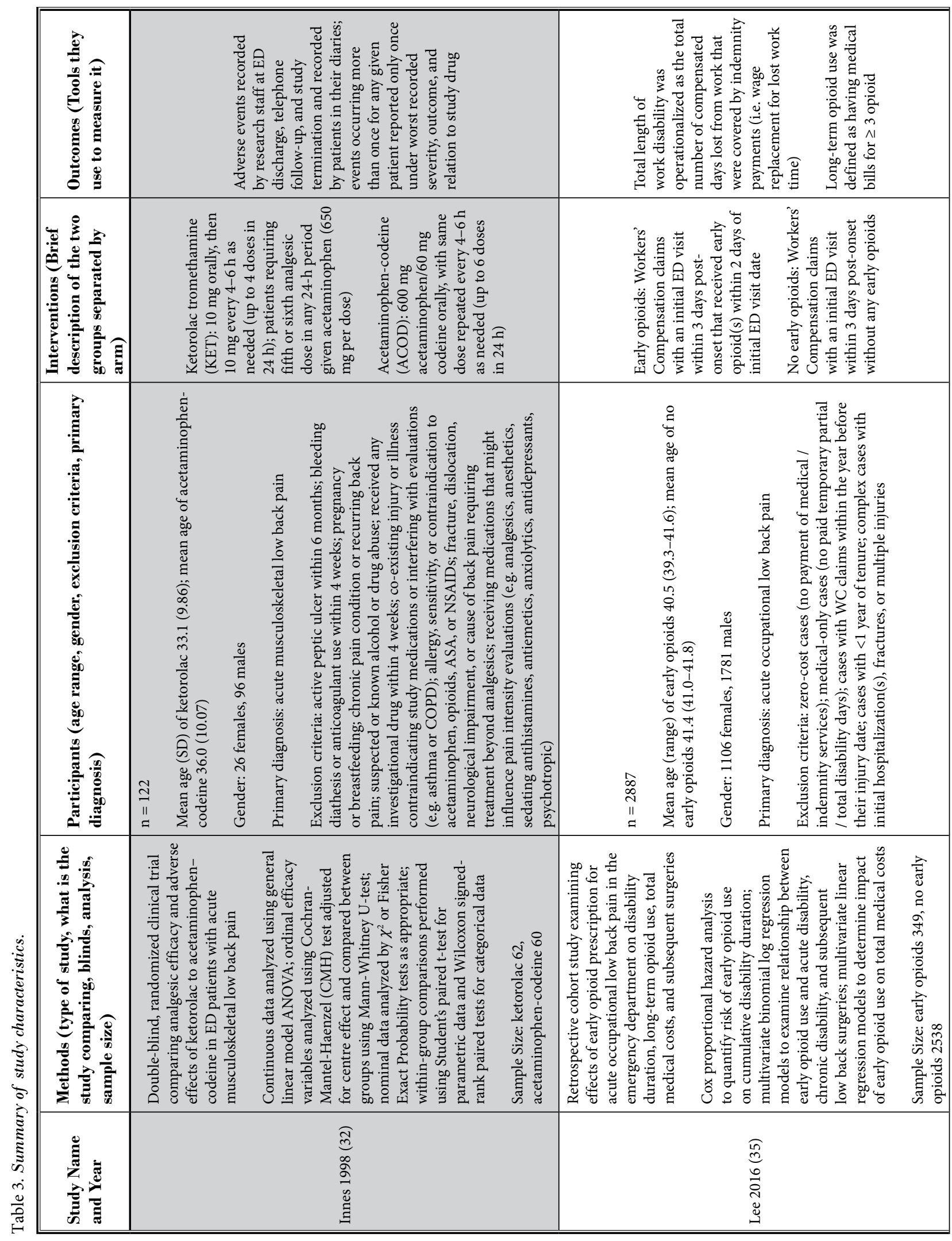




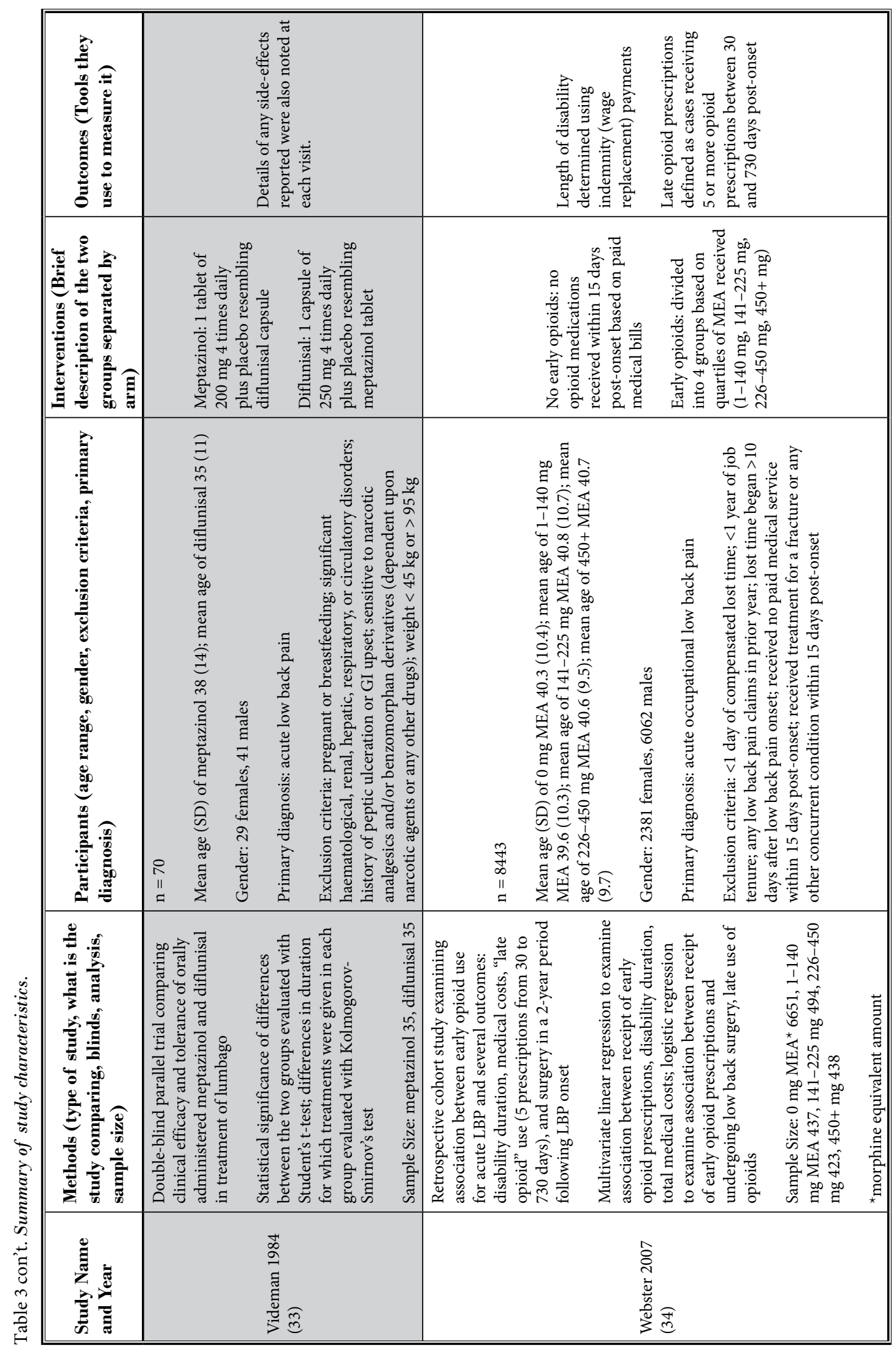




\section{Side Effects}

Side effects are defined as any adverse symptoms experienced by individuals while on any medication that was treating their ALBP. There was much heterogeneity in the side effects being measured and therefore these results were presented in a narrative summary.

\section{RESULTS}

\section{Study Selection}

From the electronic database searches, a total of 13,889 relevant abstracts were screened. After removal of 2,554 duplicates and exclusion of 11,147 studies that did not meet the inclusion criteria, the full texts of the remaining 188 articles were screened and 4 studies were included. The PRISMA flow chart for the selection process is exhibited in Fig. 1 . Of the remaining 4 studies, 2 of the studies were excluded from the metaanalysis because they did not measure the outcomes of unemployment or continued opioid use $(32,33)$. The final 2 studies that quantified outcomes of recurrent opioid use and unemployment were subjected to metaanalysis $(34,35)$.

\section{Study Characteristics}

The characteristics of the included studies in this review are summarized in Table 3. Of the 4 studies included in the systematic review, 2 were retrospective observational studies $(34,35)$ and 2 were clinical trials $(32,33)$. The 2 observational studies compared groups that did not receive any opioids when diagnosed with ALBP to groups that did receive opioids for ALBP. The RCTs compared opioid groups (metzapinol and acetaminophen-codeine) to comparator drugs (ketorolac and diflunisal) for ALBP. The mean age $(k=4)$ across intervention groups was 38.5 years, and mean age across comparator groups $(\mathrm{k}=4)$ was 37.5 years. The majority of the sample consisted of male patients (68.8\%).

Only 2 studies reported on the outcomes of continued opioid use and disability duration $(34,35)$. Two studies did not report on side effects experienced $(34,35)$ while the other 2 studies reported on adverse symptoms profiles $(32,33)$.

\section{Risk of Bias Within Studies}

The quality of each included study is shown in Table 2. Justifications for assessments are presented in Appendix III with the risk of bias tables. The Cochrane Risk of Bias and the modified Newcastle-Ottawa Scale (NOS) were used to rate the internal validity of the studies shown in Fig. 2. The Cochrane Risk of Bias tool was used to assess the quality of the RCTs and NOS was used to assess the quality of the observational studies.

Generally, the results of the RCTs included in this review should be interpreted with caution due to the risk of bias shown in Fig. 2. Some of the common issues were surprising. Specifically, one out of the 2 RCTs did not include any information on random sequence generation, blinding of patients or personnel, or blinding of outcome assessment or outcome data. This was especially surprising as blinding in drug studies is not unusual for investigators and patients. Neither RCT included any information on allocation concealment. One of the studies should especially be interpreted with caution as it was funded by the company that produces one of the drugs under investigation.

For the 2 observational studies, neither provided any information about how any missing data were handled. One of the observational studies did not adjust for confounding variables for unemployment, which places it at high risk of bias. Otherwise, the 2 studies were generally well reported on all other characteristics including an appropriate population, sample size, statistical analyses, and outcome measurement.

\section{Results of Individual Studies}

\section{Recurrent Opioid Use}

Our meta-analysis pooled results of 2 studies comparing the effects of opioid prescription use for ALBP on recurrent use of prescription opioids in the future by measuring the number of prescriptions given utilizing a prescribing database. The other 2 identified studies did not report on the outcome of recurrent opioid use $(32,33)$ (Fig. 3). Opioid prescription in Lee et al (35) was defined as receiving and filling a prescription for ALBP within 2 days of the ED visit and it was defined by Webster et al (34) as receiving and filling a prescription within 15 days of the ED visit. The total sample size consists of 9,975 patients. In Webster et al (34), prescription opioid dosage was divided into 4 quartiles that ranged from 1 to 450+ morphine equivalent amount (MEA). In Lee et al (35), the mean for MEA was 145. In this analysis, we used the results for the entire population of Lee at al (35) and the results from the 1-140 MEA group of Webster et al (34). In our meta-analysis, we used the relative risk ratio to compare the groups that received no opioid prescription to the group that did receive an opioid prescription. The relative risk ratio is defined as the risk of an event, in this case recurrent opioid use, relative to an exposure, prescription for opioids. For recurrent opioid use, we see that those who were pre- 


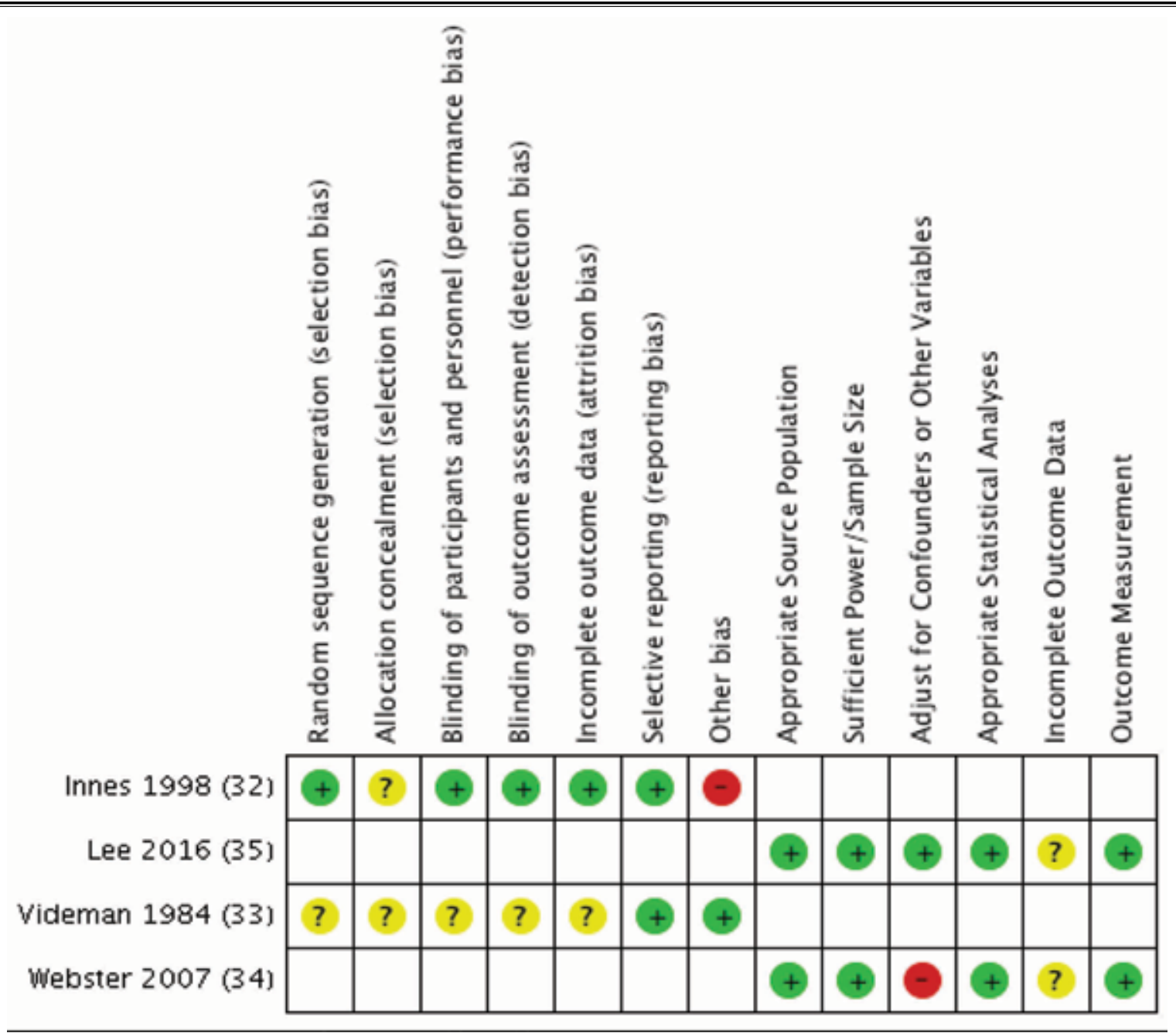

Fig. 2. Risk of bias summary: review authors' judgements about each risk of bias item for each included study. The items from random sequence generation to other bias (inclusive) are from the Cochrane Risk of Bias Tool reflecting the 2 RCTs while items from Appropriate Source Population to Outcome Measurement (inclusive) are from the Newcastle-Ottawa Scale (NOS) reflecting the 2 observational studies.

scribed opioids for ALBP were $57 \%$ (95\% Cl, 1.06-2.33) more likely to have recurrent opioid use than those who were not given an opioid prescription. However, significant heterogeneity $\left(\mathrm{I}^{2}=83 \%\right)$ is present.

\section{Unemployment}

Overall, our meta-analysis (Fig. 4) pooled results of 2 studies comparing the opioid prescription for ALBP and no opioid use, measuring outcomes of unemployment. The other 2 studies did not report quantitative data on the unemployment outcome. The total sample size consisted of 9,975 patients. Both Webster et al (34) and Lee et al (35) measured unemployment as days filed for worker's disability. Similarly, for the analysis of continued opioid use, we used the results for the 1-140 MEA from Webster at al (34) and the results of the full sample for Lee et al (35). In our meta-analysis, we used the standardized mean difference (SMD) to compare the effects of both groups. The SMD is the difference in mean effects between the intervention and comparator groups divided by the pooled standard deviation (SD). In our meta-analysis, an estimated SMD of 3.54 
Pain Physician: March/April 2019: 22:119-138

\begin{tabular}{|c|c|c|c|c|c|c|c|}
\hline \multirow[b]{2}{*}{ Study or Subgroup } & \multirow[b]{2}{*}{ log[Risk Ratio] } & \multicolumn{2}{|c|}{ Early Opioid Use No Opioid Use } & & \multirow{2}{*}{$\begin{array}{c}\text { Risk Ratio } \\
\text { IV, Random, } 95 \% \mathrm{CI}\end{array}$} & \multirow{2}{*}{\multicolumn{2}{|c|}{$\begin{array}{c}\text { Risk Ratio } \\
\text { IV, Random, } 95 \% \text { CI }\end{array}$}} \\
\hline & & Total & Total & Weight & & & \\
\hline Lee 2016 (35) & $\begin{array}{lll}0.2546 & 0.105\end{array}$ & 349 & 2538 & $51.6 \%$ & $1.29[1.05,1.58]$ & & $7-$ \\
\hline Webster 2007 (34) & 0.65750 .1269 & 437 & 6651 & $48.4 \%$ & $1.93[1.50,2.47]$ & & \\
\hline Total $(95 \% \mathrm{Cl})$ & & 786 & 9189 & $100.0 \%$ & $1.57[1.06,2.33]$ & & \\
\hline \multicolumn{6}{|c|}{ 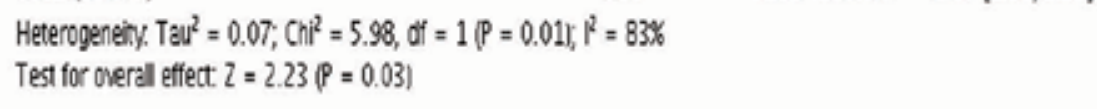 } & $\begin{array}{ll}1 & 0.5\end{array}$ & $\begin{array}{l}1.5 \\
\text { Late Opioic }\end{array}$ \\
\hline
\end{tabular}

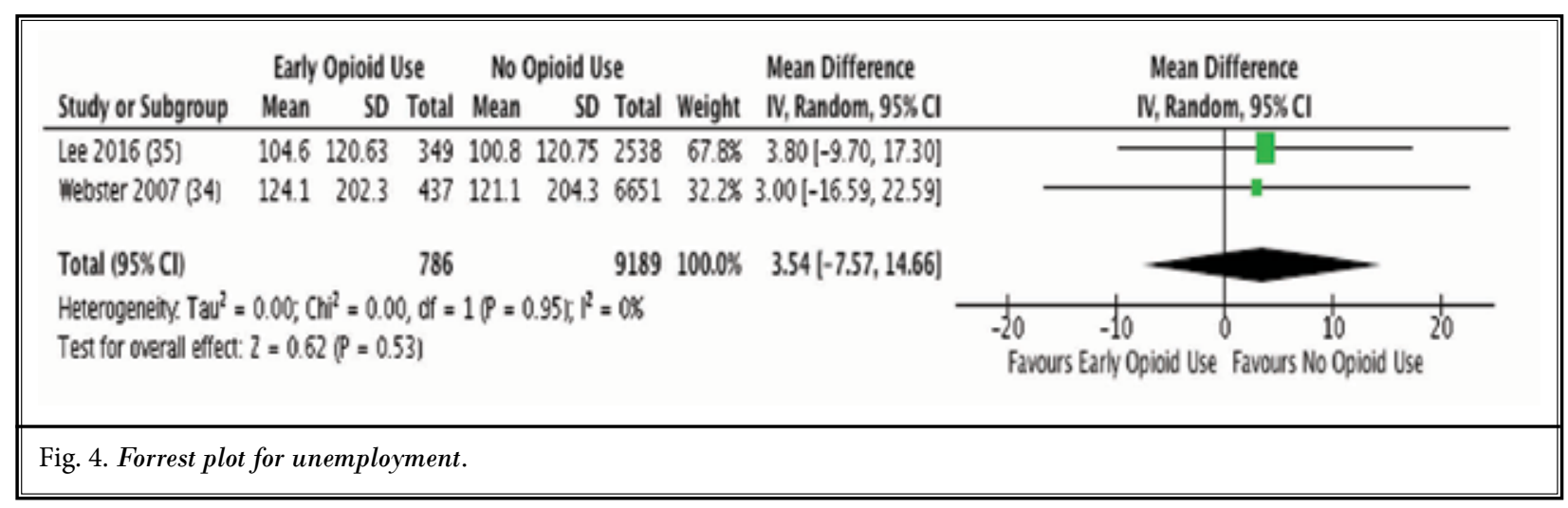

$(95 \% \mathrm{Cl},-7.57$ to 14.66$)$ was observed. These results suggest that in terms of unemployment, there is no significant association between those who had opioids prescribed for ALBP and those who did not have an opioid prescription.

\section{Side Effects}

The meta-analysis for side effects (SEs) was not possible due to high heterogeneity among the identified studies with respect to the variability of side effects considered; therefore, results have been qualitatively synthesized here. Only 2 eligible studies reported on SEs experienced. The assessment tools for measurement of SEs together with findings of the 2 studies are summarized in Table 2. While the SEs in Innes et al (32) were recorded at discharge, follow-up, and at the end of the study, Videman et al (33) only recorded the side effects at follow-ups for a total of 3 weeks. Furthermore, Innes et al (32) used a more structured approach by defining adverse drug events (ADEs) according to severity as well as employing a subjective rating scale at the termination of the study.
Both studies found a similar profile of SEs including mainly gastrointestinal and neurological symptoms experienced by patients (Table 2). Videman et al (33) also found that patients reported tiredness, sweating, and urinary symptoms. While both studies reported the number of patients affected by SEs, only Innes et al (32) described the proportion of patients with severe SEs during the study. Nevertheless, both trials reported the number of patients discontinuing treatment due to experiencing SEs during the study. In the Innes et al (32) study, twice as many SEs were reported in one intervention group compared to the other group while Videman et al (33) found comparable incidences of SEs in both of their study groups. At the study conclusion in one trial (32), the frequencies of patient self-reported overall ratings of drug tolerability as "very good" or "excellent" were $70 \%(95 \% \mathrm{Cl}, 59 \%-81 \%)$ and $46 \%$ (95\% Cl, 34\%-58\%] in the ketorolac and acetaminophen-codeine patient groups, respectively.

\section{Risk of Bias Across Studies}

When assessing risk of bias across studies (Fig. 5), 
we noticed a few trends. First, in the RCTs, neither study provided any information on selection bias. One study did not provide any information on or analysis of detection bias or attrition bias. However, both studies were found to have reporting bias. One additional form of bias was an RCT that was being funded by a company that has developed one of the drugs used. Overall, our results show that the results from the RCTs should be interpreted carefully due to risk of bias.

In the 2 observational studies, neither study reported any information on how missing data were handled, and one study did not adjust for potential confounders. However, all studies reported the appropriate population, statistical analyses, sample size, and outcome measurement. Overall, our results show that the observational studies were generally well-reported but should still be interpreted with caution, as they are not without bias.

\section{Additional Analyses}

Due to the small number of studies identified for this review, no additional analyses were conducted.

\section{Summary of Evidence}

The main cause of deaths associated with drugs in North America is linked to opioid use with misuse of prescription opioids as the primary contributing factor to the global opioid crisis (36) and economic burden on health care systems (37). Currently, after the United States, the second largest user of pharmaceutical opioids is Canada $(38,39)$. Despite recommendations from recent guidelines to perform a full risk assessment of ALBP patients before prescribing opioid analgesics $(40,41)$, prescription of opioids and misuse of these medications continue (42).

Although the therapeutic efficacy of opioids for management of chronic pain in general is wellestablished $(8,43)$, evidence for prescribing opioids for ALBP is largely lacking. It is uncertain whether opioid prescribing for patients with ALBP improves recovery rate or return to work and whether adverse SEs are associated with long-term overuse of opioids. To date, there are no systematic reviews on the evidence for long-term use of opioids and other adverse outcomes in patients affected by ALBP. Therefore, given the con-

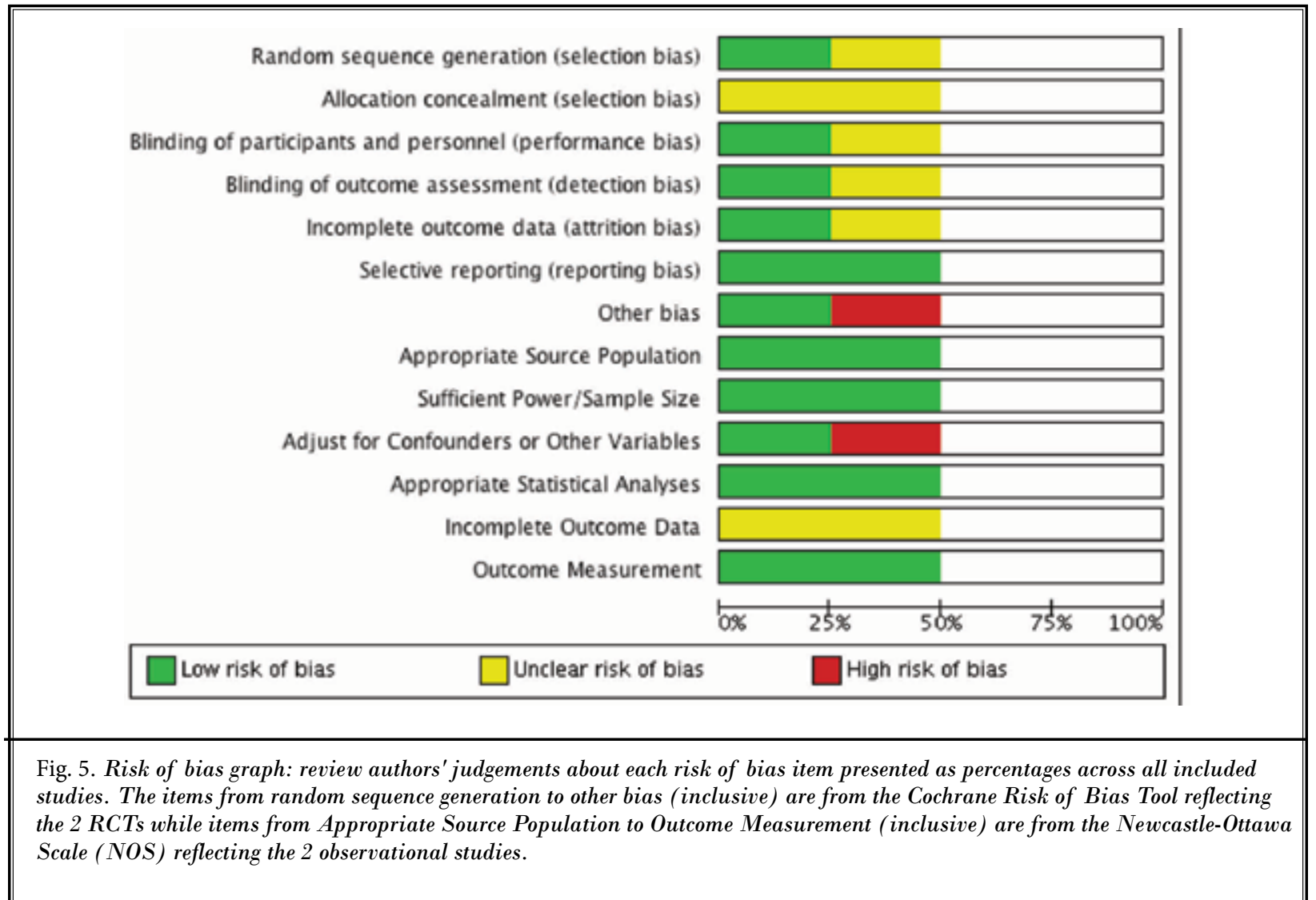


siderable negative impact of opioids and related-drug misuse outcomes, the evaluation of evidence regarding long-term functional outcomes associated with opioid overuse in ALBP patients is warranted. To the best of our knowledge, this study is the first reported metaanalysis on the synthesis of evidence for long-term opioid overuse and associated adverse outcomes in patients with ALBP. Our findings indicate that ALBP patients prescribed opioids are at risk for continuing to have long-term opioid prescription use and that opioid therapy for ALBP does not expedite return to work.

\section{Continued Opioid Use}

The meta-analysis of pooled evidence showed that there was a significant difference in recurrent opioid use in patients prescribed opioids versus non-opioid users. This suggests that opioid prescribing for patients affected by ALBP may constitute a risk factor for these patients to continue to use opioids beyond the time required for treatment of the acute condition. Previous studies have also indicated that prescribing opioids for acute pain management poses a high risk for long-term opioid overuse $(44,45)$

Furthermore, patients prescribed opioids for ALBP had double the risk of recurrent opioid use compared to those who were not given an opioid prescription. In support of our findings, several recent studies have also found higher risks of long-term opioid use and overdose associated with initial opioid exposure $(46,47)$, especially prevalent in opioid-naïve patients with acute pain (48-50). However, due to the limited number of studies for this meta-analysis and the presence of significant heterogeneity, the results should be interpreted with caution.

Recent systematic reviews have shown that as a result of the limited number of trials there is no certainty regarding the efficacy and safety of opioids in ALBP individuals $(42,51)$. There is also a lack of evidence in support of long-term opioid use at any dose in the treatment of ALBP. Our systematic review highlights the need for revising current guidelines related to prescribing opioids for ALBP treatment in light of the associated risk factors in prescribing opioids leading to recurrent and prolonged use of opioids.

\section{Disability Duration and Opioid Use}

We did not find a significant association between opioid prescription and disability duration for ALBP patients when combining study results. The findings of Webster et al (34) revealed that longer work disability was linked to prescribing as well as higher doses of opioids despite adjusting for injury severity and demographic factors. This could be due to the negative effect of opioids on physiological well-being or to patients' greater risk of poor outcomes independent of opioids (42). Lee et al (35), however, did not find an association between opioid prescribing and disability duration. These studies do not seem to indicate that opioids accelerate patients' return to work or improve functional outcomes. Previous studies showed that prescribing opioids for acute pain was associated with negative consequences; in a study of primary care patients, patients with acute pain who were prescribed opioids were found to have worsening of pain, function, and depression after 6 months compared to those who did not receive opioids (52). In a study of acute pain related to work injuries, patients receiving opioids for more than one week were twice as likely to experience longterm disability after one year (53).

\section{Side Effects of Opioid Use for ALBP management}

Although there was no quantitative analysis possible for SEs, this review included studies of both observational and nonplacebo designs. We found that the most commonly reported SEs of opioids in patients with ALBP were gastrointestinal and neurological symptoms. Other reported SEs included urinary symptoms, tiredness, and sweating (33). Other studies have reported similar SEs when patients were administered opioids for acute and chronic pain (54-56). The considerable heterogeneity and variability in SEs among the included studies and low number of eligible trials posed a challenge to comparing SEs of different opioids. In addition, the 2 identified trials were both randomized parallel group designs comparing opioids to other types of analgesics, with opioids demonstrating a significantly higher rate of SEs. The reported overall rates of SEs due to opioid medication (65\%) were similar in the 2 randomized trials. SEs due to long-term use of opioids in patients with ALBP are not clear from the trials included, as the longest follow-up period was 3 weeks. There were also differences in the 2 included trials in terms of patient clinical demographics such as previous exposure to opioids, severity of pain, or dose of opioid medication administered during the trial. These factors may all impact the incidence of SEs and should be taken into account in the design of future trials.

The prevalence of SEs may also depend on methods used for collection of information (56), which varied 
across the studies. Of note, both randomized clinical trials included mostly healthy young male patients who may recover more rapidly or have higher pain thresholds compared to the elderly or those with comorbid illness. Other factors that may explain the differences in the reporting of the 2 randomized clinical trials include differences in the duration of pain assessment, ranging from a few hours to weekly assessment. Therefore, these findings cannot be generalized to the wider population, and larger scale clinical trials with longer duration of follow-up are warranted to determine the influences of gender, age, or other demographic factors on reported SEs.

\section{Limitations}

Despite the strengths of this systematic review (such as adherence to PRISMA guidelines and publication of a protocol), there are potential limitations to consider. For the analysis of unemployment, we were only able to conduct an unpooled analysis. Although we did attempt a meta-analysis, publication bias could not be assessed due to the limited number of studies. There was both statistical and clinical heterogeneity among the included studies, due to differences in methodology, study design, risk of selection, or performance bias - which has been known to potentially affect meta-analysis (58). In addition, most of the studies had an unclear or high risk of bias and poorly defined SEs. Despite such limitations, the rapid rise in prescriptionrelated opioid complications, including mortality due to overdose, makes this systematic review needed and raises the need for further studies to provide evidence on the efficacy and safety of long-term opioid treatment for patients with ALBP.
There is limited evidence to determine benefits and adverse effects of opioids in various subgroups of patients defined by clinical or demographic characteristics. When facing challenges with randomized clinical trials, well-designed observational studies with control of potential confounding factors are much needed to investigate the efficacy and safety of long-term opioid use in patients with ALBP. Moreover, additional research is needed to compare the benefits and safety of various opioids and dosages.

Therefore, definitive conclusions on the effectiveness of long-term opioid therapy for acute back pain are not possible due to the scarcity of clinical evidence. Within the limitations of this review, however, significant risks appear to be associated with opioid prescription for acute pain management, whereby no improvement is found in employment status and risk of continued use is evident.

\section{Conclusions}

This systematic review demonstrates that patients with ALBP who are prescribed opioids are at a significantly higher risk of continued opioid use. Furthermore, prescribing opioids for ALBP patients is associated with at least one adverse event and delayed recovery. The findings of this systematic review, in addition to the widespread opioid-prescribing trend, further highlight the urgent need to conduct randomized trials to provide (a) evidence on the efficacy and safety of pharmaceutical opioids in the treatment of patients with ALBP or (b) evidence-based guidelines to avoid prescribing opioids for ALBP. 
Appendix 1. Complete search strategy.

\begin{tabular}{|c|c|}
\hline MEDLINE=669 & $\begin{array}{ll}1 & \text { exp Acute Pain } \\
2 & \text { exp Low Back Pain } \\
3 & \text { exp Analgesics, Opioid } \\
4 & \text { exp Morphine } \\
5 & \text { exp Codeine } \\
6 & \text { exp Fentanyl } \\
7 & \text { exp Tramadol } \\
8 & \text { exp Meptazinol } \\
9 & \text { exp Pentazocine } \\
10 & \text { exp Methadone } \\
11 & \text { exp Buprenorphine } \\
12 & \text { oxycodone.mp. } \\
13 & \text { dipipanone.mp. } \\
14 & \text { remifentanil.mp. } \\
15 & \text { papaveretum.mp. } \\
16 & \text { pethidine.mp. } \\
17 & \text { tapentadol.mp. } \\
18 & 1 \text { or } 2 \\
19 & 3 \text { or } 4 \text { or } 5 \text { or } 6 \text { or } 7 \text { or } 8 \text { or } 9 \text { or } 10 \text { or } 11 \text { or } 12 \text { or } 13 \text { or } 14 \text { or } 15 \text { or } 16 \text { or } 17 \\
20 & 18 \text { and } 19 \text { (728) } \\
21 & \text { limit } 20 \text { to humans }(701) \\
\end{array}$ \\
\hline $\mathrm{EMBASE}=6,565$ & $\begin{array}{ll}1 & \text { exp pain } \\
2 & \text { exp low back pain } \\
3 & \text { exp narcotic analgesic agent } \\
4 & \text { exp morphine } \\
5 & \text { exp codeine } \\
6 & \text { exp fentanyl } \\
7 & \text { exp tramadol } \\
8 & \text { exp meptazinol } \\
9 & \text { exp pentazocine } \\
10 & \text { exp methadone } \\
11 & \text { exp buprenorphine } \\
12 & \text { oxycodone.mp. } \\
13 & \text { dipipanone.mp. } \\
14 & \text { remifentanil.mp. } \\
15 & \text { papaveretum.mp. } \\
16 & \text { pethidine.mp. } \\
17 & \text { tapentadol.mp. } \\
18 & \text { acute pain.mp. } \\
19 & 1 \text { or } 2 \text { or } 18 \\
20 & 3 \text { or } 4 \text { or } 5 \text { or } 6 \text { or } 7 \text { or } 8 \text { or } 9 \text { or } 10 \text { or } 11 \text { or } 12 \text { or } 13 \text { or } 14 \text { or } 15 \text { or } 16 \text { or } 17 \\
21 & 19 \text { and } 20 \\
22 & 1 \text { and } 18 \\
23 & 2 \text { or } 22 \\
24 & 20 \text { and } 23\end{array}$ \\
\hline PsycINFO=247 & $\begin{array}{ll}1 & \text { exp Pain } \\
2 & \text { exp Back Pain } \\
3 & 1 \text { and } 2 \\
4 & \text { low back pain.mp. } \\
5 & \text { acute pain.mp. } \\
6 & \text { exp Opiates } \\
7 & \text { exp MORPHINE } \\
8 & \text { exp CODEINE } \\
9 & \text { exp TRAMADOL } \\
10 & \text { exp PENTAZOCINE } \\
11 & \text { exp FENTANYL } \\
12 & \text { exp METHADONE } \\
13 & \text { meptazinol.mp. } \\
14 & \text { exp BUPRENORPHINE } \\
15 & \text { oxycodone.mp. } \\
16 & \text { dipipanone.mp. } \\
17 & \text { remifentanil.mp. } \\
18 & \text { papaveretum.mp. } \\
19 & \text { pethidine.mp. } \\
20 & \text { tapentadol.mp. } \\
21 & 3 \text { or } 4 \text { or } 5 \\
22 & 6 \text { or } 7 \text { or } 8 \text { or } 9 \text { or } 10 \text { or } 11 \text { or } 12 \text { or } 13 \text { or } 14 \text { or } 15 \text { or } 16 \text { or } 17 \text { or } 18 \text { or } 19 \text { or } 20 \\
23 & 21 \text { and } 22\end{array}$ \\
\hline
\end{tabular}


Appendix 1 con't. Complete search strategy.

\begin{tabular}{|c|c|}
\hline Web of Science $=5,511$ & $\begin{array}{ll}1 & \text { TS=acute pain } \\
2 & \text { TS=low back pain } \\
3 & \text { TS=analgesics, opioid } \\
4 & \text { TS=morphine } \\
5 & \text { TS= codeine } \\
6 & \text { TS= tramadol } \\
7 & \text { TS= pentazocine } \\
8 & \text { TS= fentanyl } \\
9 & \text { TS= methadone } \\
10 & \text { TS= meptazinol } \\
11 \text { TS= buprenorphine } \\
12 \text { TS= oxycodone } \\
13 \text { TS= dipipanone } \\
14 \text { TS= remifentanil } \\
15 \text { TS= papaveretum } \\
16 \text { TS= pethidine } \\
17 \text { TS= tapentadol } \\
18 \text { \#2 OR \#1 } \\
19 \text { \#17 OR \#16 OR \#15 OR \#14 OR \#13 OR \#12 OR \#11 OR \#10 OR \#9 OR \#8 OR \#7 OR \#6 OR \#5 OR \#4 OR \#3 } \\
20 \text { \#19 AND \#18 }\end{array}$ \\
\hline CINAHL $=229$ & $\begin{array}{l}1 \text { MM "Acute Pain (Saba CCC)") OR (MM "Pain Clinics") OR "acute pain" } \\
2 \text { MM "Low Back Pain" } \\
3 \text { MH "Analgesics, Opioid+" } \\
4 \text { MH "Morphine+" } \\
5 \text { MH "Codeine+" } \\
6 \text { MM "Tramadol" } \\
7 \text { MH "Fentanyll" } \\
8 \text { "meptazinol" } \\
9 \text { MH "Pentazocine" } \\
10 \text { MH "Methadone" } \\
11 \text { MH "Buprenorphine" } \\
12 \text { MH "Oxycodone" } \\
13 \text { "dipipanone" } \\
14 \text { "remifentanil" } \\
15 \text { "papaveretum" } \\
16 \text { "pethidine" } \\
17 \text { "tapentadol" } \\
18 \text { S1 OR S2 } \\
19 \text { S3 OR S4 OR S5 OR S6 OR S7 OR S8 OR S9 OR S10 OR S11 OR S12 OR S13 OR S14 OR S15 OR S16 OR S17 } \\
20 \text { S18 AND S19 }\end{array}$ \\
\hline $\begin{array}{l}\text { Cochrane Library and } \\
\text { Clinical Trials Registry= } \\
179\end{array}$ & $\begin{array}{l}1 \text { remifentanil } \\
2 \text { papaveretum } \\
3 \text { pethidine } \\
4 \text { tapentadol } \\
5 \text { MeSH descriptor: [Acute Pain] explode all trees } \\
6 \mathrm{MeSH} \text { descriptor: [Low Back Pain] explode all trees } \\
7 \mathrm{MeSH} \text { descriptor: [Analgesics, Opioid] explode all trees } \\
8 \mathrm{MeSH} \text { descriptor: [Morphine] explode all trees } \\
9 \mathrm{MeSH} \text { descriptor: [Codeine] explode all trees } \\
10 \mathrm{MeSH} \text { descriptor: [Fentanyl] explode all trees } \\
11 \mathrm{MeSH} \text { descriptor: [Tramadol] explode all trees } \\
12 \mathrm{MeSH} \text { descriptor: [Meptazinol] explode all trees } \\
13 \mathrm{MeSH} \text { descriptor: [Pentazocine] explode all trees } \\
14 \mathrm{MeSH} \text { descriptor: [Methadone] explode all trees } \\
15 \mathrm{MeSH} \text { descriptor: [Buprenorphine] explode all trees } \\
16 \mathrm{MeSH} \text { descriptor: [Oxycodone] explode all trees } \\
17 \text { dipipanone } \\
18 \# 5 \text { or \#6 } \\
19 \# 1 \text { or \#2 or \#3 or \#4 or \#7 or \#8 or \#9 or \#10 or \#11 or \#12 or \#13 or \#14 or } 15 \text { or \#16 or \#17 } \\
20 \# 18 \text { and \#19 }\end{array}$ \\
\hline $\begin{array}{l}\text { National Institutes for } \\
\text { Health Clinical Trials } \\
\text { Registry }=207\end{array}$ & $\begin{array}{l}\text { Condition or disease terms: acute pain, low back pain } \\
\text { Intervention terms: opioids, analgesics, prescription }\end{array}$ \\
\hline $\begin{array}{l}\text { World Health } \\
\text { Organization International } \\
\text { Clinical Trials Registry } \\
\text { Platform }=288\end{array}$ & acute pain OR low back pain AND opioids \\
\hline
\end{tabular}


Appendix 2.

Data Extraction Form

Study ID Reviewer Initials

Publication Details

Author (last name, first initial): Year:

Title:

Journal: Country:

Methods

Study design: Study setting:

Length of study:

Description of sample:

Definition of ALBP:

Exposure: Intervention (if applicable):

Demographics

Number of participants: Total: Men: Women: Per group:

Mean age (SD): Total: Men: Women:

Per group:

Ethnicity:

Outcome measurements:

Efficacy outcome

Schober test:

Pain measurement:

Oswestry disability questionnaire:

Modified Zung questionnaire:

Modified somatic perception questionnaire: 
Adverse events outcome:

Incidence of misuse:

Opioid withdrawal symptoms:

Physical adverse events:

Social adversity:

Mortality:

Comments:

Results

Statistical methods: Adjusted for:

Coefficient: 95\% CI: p-value:

Findings:

Limitations:

Inclusion Criteria

RCT or observational study design examining outcome of prescription opioid use for ALBP Participants aged 18 years or older

Exclusion Criteria

Pilot or feasibility studies

Patients with comorbid use disorder

Additional Comments: 
Appendix 3

\begin{tabular}{|c|c|c|}
\hline \multicolumn{3}{|l|}{ Videman 1984 (33) } \\
\hline Study Identification & Author Judgment & Justification \\
\hline Random Sequence Generation & Unclear Risk & No information provided \\
\hline Allocation Concealment (Selection Bias) & Unclear Risk & No information provided \\
\hline Blinding of Participants and Personnel & Unclear Risk & Study described as double-blind, but no information on blinding provided \\
\hline Blinding of Outcome Assessment & Unclear Risk & Study described as double-blind, but no information on blinding provided \\
\hline Incomplete Outcome Data & Unclear Risk & No information provided \\
\hline Selective Reporting & Low Risk & All prespecified outcomes were reported \\
\hline Other & Low Risk & No other biases apparent \\
\hline
\end{tabular}

\begin{tabular}{|c|c|c|}
\hline \multicolumn{3}{|l|}{ Innes $1998(32)$} \\
\hline Study Identification & Author Judgment & Justification \\
\hline Random Sequence Generation & Low Risk & $\begin{array}{l}\text { Patients allocated to groups based on a computer-generated randomization } \\
\text { code }\end{array}$ \\
\hline Allocation Concealment (Selection Bias) & Unclear Risk & No information provided \\
\hline Blinding of Participants and Personnel & Low Risk & All drugs were prepared in identical capsules to preserve double-blinding \\
\hline Blinding of Outcome Assessment & Low Risk & A blinded consultant entered all data and performed statistical analyses \\
\hline Incomplete Outcome Data & Low Risk & $\begin{array}{l}\text { Missing values for efficacy assessments performed during the first } 6 \\
\mathrm{~h} \text { interval were interpolated or extrapolated as follows: if one or more } \\
\text { sequential evaluations were missing because the data were not recorded or } \\
\text { the patients were not available to complete the assessment, then data were } \\
\text { interpolated in a linear fashion; patients who required a second analgesic } \\
\text { dose within } 6 \mathrm{~h} \text { of the first had their missing }(5 \text { and } 6 \mathrm{~h} \text { ) values interpolated } \\
\text { using the worst of the baseline rating or the last rating prior to the second } \\
\text { dosing; patients withdrawing from the study before } \mathrm{T}=6 \mathrm{~h} \text { had missing } \\
\text { values recorded as the last rating prior to discontinuation }\end{array}$ \\
\hline Selective Reporting & Low Risk & All prespecified outcomes were reported \\
\hline Other & High Risk & $\begin{array}{l}\text { Study funded by company which produces one of the drugs under } \\
\text { investigation (Ketorolac) }\end{array}$ \\
\hline
\end{tabular}

\begin{tabular}{|c|c|c|}
\hline \multicolumn{3}{|l|}{ Lee 2016 (35) } \\
\hline Study Identification & Author Judgment & Justification \\
\hline Appropriate Source Population & Low Risk & $\begin{array}{l}\text { Consecutive sample from a population representative of the condition under } \\
\text { study }\end{array}$ \\
\hline Sufficient Power/Sample Size & Low Risk & Large sample size $(\mathrm{N}=2887)$ \\
\hline $\begin{array}{l}\text { Adjust for Confounders or Other } \\
\text { Variables }\end{array}$ & High Risk & $\begin{array}{l}\text { Several covariates included to adjust for individual characteristics and injury } \\
\text { severity but did not adjust for covariates in all outcomes of interest. }\end{array}$ \\
\hline Appropriate Statistical Analyses & Low Risk & Reported use of appropriate statistical analysis as required \\
\hline Incomplete Outcome Data & Unclear Risk & No information provided \\
\hline Outcome Measurement & Low Risk & $\begin{array}{l}\text { Provided a detailed description of the outcome measures which are } \\
\text { appropriate for the outcome of interest }\end{array}$ \\
\hline Follow-up Bias & Unclear Risk & No information provided \\
\hline
\end{tabular}


Appendix 3 con't.

\begin{tabular}{|c|c|c|}
\hline \multicolumn{3}{|l|}{ Webster 2007 (34) } \\
\hline Study Identification & Author Judgment & Justification \\
\hline Appropriate Source Population & Low Risk & $\begin{array}{l}\text { Consecutive sample from a population representative of the } \\
\text { condition under study }\end{array}$ \\
\hline Sufficient Power/Sample Size & Low Risk & Large sample size $(\mathrm{N}=8443)$ \\
\hline Adjust for Confounders or Other Variables & High Risk & $\begin{array}{l}\text { Covariates included age, gender, job tenure, and low back } \\
\text { injury severity group }\end{array}$ \\
\hline Appropriate Statistical Analyses & Low Risk & Reported use of appropriate statistical analysis as required \\
\hline Incomplete Outcome Data & Unclear Risk & No information provided \\
\hline Outcome Measurement & Low Risk & $\begin{array}{l}\text { Provided a detailed description of the outcome measures } \\
\text { which are appropriate for the outcome of interest }\end{array}$ \\
\hline Follow-up Bias & Unclear Risk & No information provided \\
\hline
\end{tabular}

\section{REFERENCES}

1. Hart LG, Deyo RA, Cherkin DC. Physician office visits for low back pain: Frequency, clinical evaluation, and treatment patterns from a US national survey. Spine (Phila Pa 1976) 1995; 20:11-19.

2. Deyo RA, Mirza SK, Martin BI. Back pain prevalence and visit rates: Estimates from US national surveys, 2002. Spine (Phila Pa 1976) 2006; 31:2724-2727.

3. Hoy D, March L, Brooks P, Blyth F, Woolf A, Bain C. The global burden of low back pain: Estimates from the Global Burden of Disease 2010 study. Ann Rheum Dis 2014; 73:968-974.

4. Ehrlich GE. Low back pain. Bull World Heal Organ 2003; 81:671-676.

5. Van Tulder $M$, Becker A, Bekkering $T$, Breen A, del Real MT, Hutchinson A, Koes B, Laerum E, Malmivaara A. Chapter 3. European guidelines for the management of acute nonspecific low back pain in primary care. Eur spine J 2006; 15:S169-s191.

6. Coste J, Delecoeuillerie G, Cohen de Lara AC, LeParc J, Paolaggi J. Clinical course and prognostic factors in acute low back pain: An inception cohort study in primary care practice. BMJ 1994; 308:577-580.

7. Pengel LH, Herbert RD, Maher CG, Refshauge KM. Acute low back pain: Systematic review of its prognosis. BM] 2003; 327:323.

8. Chou R, Huffman LH. Medications for acute and chronic low back pain: A review of the evidence for an American
Pain Society/American College of Physicians clinical practice guideline. Ann Intern Med 2007; 147:505-514.

9. Casazza BA. Diagnosis and treatment of acute low back pain. Am Fam Physician 2012; 85:343-50.

10. Goertz M, Thorson D, Bonsell J, Campbell R, Kuku O, Mueller B, Locketz A. Adult acute and subacute low back pain. Bloomington, MN: Institute for Clinical Systems Improvement; 2012. https:// www.icsi.org/_asset/bjvqrj/LBP.pdf. Updated November 2012. Accessed June 1, 2017.

11. Mclntosh $G$, Hall $H$. Low back pain (acute). BMJ Clin Evid 2011; 2011:1102.

12. Ashworth J, Green DJ, Dunn KM, Jordan KP. Opioid use among low back pain patients in primary care: Is opioid prescription associated with disability at 6-month follow-up? Pain 2013; 154:1038-1044.

13. Chou R, Qaseem A, Snow V, Casey D, Cross JT, Shekelle P, Owens DK. Diagnosis and treatment of low back pain: $\mathrm{A}$ joint clinical practice guideline from the American College of Physicians and the American Pain Society. Ann Intern Med 2007; 147:478-491.

14. Deyo RA, Von Korff M, Duhrkoop D. Opioids for low back pain. BM] 2015; 350:g6380.

15. Volinn E, Fargo JD, Fine PG. Opioid therapy for nonspecific low back pain and the outcome of chronic work loss. Pain. 2009; 142:194-201.

16. Deyo RA, Smith DHM, Johnson ES,
Donovan M, Tilloston CJ, Yang X, Petrik A, Dobscha SK. Opioids for back pain patients: Primary care prescribing patterns and use of services. J Am Board Fam Med 2011; 24:717-727.

17. Edlund MJ, Martin BC, Devries A, Fan $M-Y$, Braden JB, Sullivan MD. Trends in use of opioids for chronic non-cancer pain among individuals with mental health and substance use disorders: The TROUP study. Clin J Pain 2010; 26:1-8.

18. Fischer B, Rehm J, Brissette S, Brochu S, Bruneau J, El-Guebaly N, Noel L, Tyndall M, Wild C, Mun P, Baliunas D. Illicit opioid use in Canada: Comparing social, health, and drug use characteristics of untreated users in five cities (OPICAN study). J Urban Heal 2005; 82:250-266.

19. Davison C, Perron M. First Do No Harm: Responding to Canada's Prescription Drug Crisis. Ottawa, ON: Canadian Centre on Substance Abuse; 2013.

20. Gomes T, Mamdani MM, Dhalla IA, Cornish S, Paterson JM, Juurlink DN. The burden of premature opioid-related mortality. Addiction 2014; 109:1482-1488.

21. Schuckit MA. Treatment of opioid-use disorders. N Engl] Med 2016; 375:357-368.

22. Subramaniam GA, Stitzer MA. Clinical characteristics of treatment-seeking prescription opioid vs. heroin-using adolescents with opioid use disorder. Drug Alcohol Depend 2009; 101:13-19.

23. Bawor $M$, Dennis BB, Varenbut $M$, Daiter J, Marsh DC, Plater C, Worster A, Steiner M, Anglin R, Pare G, Desai D, Thabane L, Samaan Z. Sex differences in 
substance use, health, and social functioning among opioid users receiving methadone treatment: A multicenter cohort study. Biol Sex Differ 2015; 6:21.

24. American Psychiatric Association. Diagnostic and statistical manual of mental disorders $\left(D S M-5^{\circledR}\right)$. 5th ed. Washington, DC: American Psychiatric Publishing; 2013

25. Moher D, Liberati A, Tetzlaff J, Altman DG; PRISMA Group. Preferred reporting items for systematic reviews and metaanalyses: The PRISMA statement. PLoS Med 2009; 6:e1000097.

26. Mouravska $N$, Zielinski L, Bhatt $M$, Sanger N, Bawor M, Dennis B, Banfield L, MacKillop J, Paul J, Worster A, Laplante $P$, Thabane L, Samaan Z. Adverse outcomes associated with opioid prescription for acute low back pain: A systematic review protocol. Syst Rev 2017; 6:163.

27. Bawor M, Dennis BB, Anglin R, Steiner $M$, Thabane L, Samaan Z. Sex differences in outcomes of methadone maintenance treatment for opioid addiction: A systematic review protocol. Syst Rev 2014; 3:45.

28. Higgins JPT, Altman DG, Gøtzsche PC, Juni P, Moher D, Oxman AD, Savovic J, Schulz KF, Weeks L, Sterne JAC. The Cochrane Collaboration's tool for assessing risk of bias in randomised trials. BM] 2011; 343:d5928.

29. Guyatt $\mathrm{GH}$, Oxman $A D$, Schünemann HJ, Tugwell P, Knottnerus A. GRADE guidelines: A new series of articles in the Journal of Clinical Epidemiology. J Clin Epidemiol 2011; 64:380-382.

30. Higgins JPT, Green S. Cochrane Handbook for Systematic Reviews of Interventions. Vol 4. John Wiley \& Sons, Hoboken, NJ; 2011.

31. Lau J, loannidis JPA, Terrin N, Schmid $\mathrm{CH}$, Olkin I. Evidence based medicine: The case of the misleading funnel plot. BM] 2006; 333:597-600.

32. Innes G, Croskerry P, Worthington J, Beveridge R, Jones D. Ketorolac versus acetaminophen-codeine in the emergency department treatment of acute low back pain. J Emerg Med 1998; 16:549-556.

33. Videman T, Heikkilä J, Partanen T. Double-blind parallel study of meptazinol versus diflunisal in the treatment of lumbago. Curr Med Res Opin 1984; 9:246-252.

34. Webster BS, Verma SK, Gatchel RJ. Relationship between early opioid prescribing for acute occupational low back pain and disability duration, medical costs, subsequent surgery and late opioid use.
Spine (Phila Pa 1976) 2007; 32:2127-2132.

35. Lee SS, Choi Y, Pransky GS. Extent and impact of opioid prescribing for acute occupational low back pain in the emergency department. J Emerg Med 2016; 50:376-384.

36. Rudd RA, Aleshire N, Zibbell JE, Gladden RM. Increases in drug and opioid overdose deaths - United States, 2000-2014. Centers Dis Control Prev MMWR 2016; 64:1378-1382.

37. Degenhardt L, Hall W. Extent of illicit drug use and dependence, and their contribution to the global burden of disease. Lancet 2012; 379:55-70.

38. Nosyk B, Marshall BDL, Fischer B, Montaner JSG, Wood E, Kerr T. Increases in the availability of prescribed opioids in a Canadian setting. Drug Alcohol Depend 2012; 126:7-12.

39. Darnall BD, Stacey BR, Chou R. Medical and psychological risks and consequences of long-term opioid therapy in women. Pain Med 2012; 13:1181-1211.

40. Cantrill S V, Brown MD, Carlisle RJ, Delaney KA, Hays DP, Nelson LS, O'Connor RE, Papa A, Sporer KA, Todd KH, Whitson RR. Clinical policy: Critical issues in the prescribing of opioids for adult patients in the emergency department. Ann Emerg Med 2012; 60:499-525.

41. Qaseem A, Wilt TJ, McLean RM, Forciea MA. Noninvasive treatments for acute, subacute, and chronic low back pain: A clinical practice guideline from the American College of Physicians. Ann Intern Med 2017; 166:514-530.

42. Deyo RA, Von Korff M, Duhrkoop D. Opioids for low back pain. BMJ 2015; 350:g6380.

43. Kalso E, Edwards JE, Moore RA, McQuay HJ. Opioids in chronic non-cancer pain: Systematic review of efficacy and safety. Pain 2004; 112:372-380.

44. Shah A, Hayes CJ, Martin BC. Characteristics of initial prescription episodes and likelihood of long-term opioid useUnited States, 2006-2015. MMWR Morb Mortal Wkly Rep 2017; 66:265-269.

45. Harbaugh CM, Lee JS, Hu HM, McCabe SC . Persistent opioid use among pediatric patients after surgery. Pediatrics 2018; 141:e20172439.

46. Brat GA, Agniel D, Beam A, Yorkgitis B, Bicket M, Homer M, Fox KP, Knecht DB, McMahill-Walraven CN, Palmer N, Kohane I. Postsurgical prescriptions for opioid naive patients and association with overdose and misuse: Retrospective cohort study. BM] 2018; 360:j5790.

47. Shah A, Hayes CJ, Martin BC. Factors in- fluencing long-term opioid use among opioid naive patients: An examination of initial prescription characteristics and pain etiologies. J Pain 2017; 18:1374-1383.

48. Brummett CM, Waljee JF, Goesling J, Moser S, Lin P, Englesbe MJ, Bohnert ASB, Kheterpal S, Nallamothu BK. New persistent opioid use after minor and major surgical procedures in US adults. JAMA Surg 2017; 152:e170504-e170504.

49. Bateman BT, Franklin JM, Bykov K, Avorn J, Shrank WH, Brennan TA, Landon JE, Rathmell JP, Huybrechts KF, Fischer MA, Choudry NK. Persistent opioid use following cesarean delivery: Patterns and predictors among opioidnaive women. Am J Obstet Gynecol 2016; 215:353.

50. Sun EC, Darnall BD, Baker LC, Mackey $\mathrm{S}$. Incidence of and risk factors for chronic opioid use among opioid-naive patients in the postoperative period. JAMA Intern Med 2016; 176:1286-1293.

51. Shaheed CA, Maher CG, Williams KA, Day R, McLachlan AJ. Efficacy, tolerability, and dose-dependent effects of opioid analgesics for low back pain: A systematic review and meta-analysis. JAMA Intern Med 2016; 176:958-968.

52. Von Korff M, Saunders K, Ray GT, Boudreau D, Campbell C, Merrill J, Sullivan MD, Rutter C, Silverberg M, BantaGreen C, Weisner C. Defacto long-term opioid therapy for non-cancer pain. Clin J Pain 2008; 24:521-527.

53. Franklin GM, Stover BD, Turner JA, Fulton-Kehoe D, Wickizer TM. Early opioid prescription and subsequent disability among workers with back injuries: The disability risk identification study cohort. Spine (Phila Pa 1976) 2008; 33:199-204.

54. Ricardo Buenaventura M, Rajive Adlaka M, Nalini Sehgal M. Opioid complications and side effects. Pain Physician 2008; 11:S105-S120.

55. Carr DB, Goudas LC. Acute pain. Lancet 1999; 353:2051-2058.

56. Furlan AD, Sandoval JA, Mailis-Gagnon A, Tunks E. Opioids for chronic noncancer pain: A meta-analysis of effectiveness and side effects. Can Med Assoc J 2006; 174:1589-1594.

57. Edwards JE, McQuay HJ, Moore RA, Collins SL. Reporting of adverse effects in clinical trials should be improved: Lessons from acute postoperative pain. J Pain Symptom Manage 1999; 18:427-437.

58. Moore RA. Pain and systematic reviews. Acta Anaesthesiol Scand 2001; 45:1136-1139. 